\title{
Impact of Noise on Hearing Amongst Commercial Motor Bike Riders in Benin- City, Nigeria.
}

\author{
Ibhazehiebo, K*; Ighoroje, A .D .A*, Uche, O.K*, Ogisi F.O** \& IYAWE V. I*
}

\begin{abstract}
The ambient noise level and noise-induced hearing impairment (NIHI) in 200 motorbike riders from six motorbike parks were evaluated. All were males aged between 20- 62 years. Subjects were sampled using a cluster sampling technique. Parameters measured were environmental noise using the noise meter (peters) and hearing function using an audiometer (amplaid). A control group of 150 males was selected from amongst the staff of the University of Benin Teaching Hospital and students of University of Benin after informed consent was obtained.

The mean ambient noise for motor bike riders was $90 \pm 10 \mathrm{~dB}$ a level significantly $(x=0.000)$, higher than the International Standard Organization (ISO) standard of $60 \mathrm{~dB}$. That for control group was $50 \pm 10 \mathrm{~dB}$. While there was no NIHI in control group, a significant hearing impairment for both air conduction (AC) and Bone conduction (BC) was observed in the study group. Unlike previous observations AC and BC impairment were predominantly in the left ear. Development of both $\mathrm{AC}$ and $\mathrm{BC}$ impairments increased with period of exposure.

Environment noise impacts adversely on hearing and is a risk factor in commercial motorbike riders. Development of NIHI is significantly higher in the left ear than right unlike in other occupations.
\end{abstract}

\section{INTRODUCTION}

Occupational noise remains a serious urban disease 1 . Evidence has accumulated that noise is a risk factor in sleep disturbance, cardiovascular dysfunction, speech interference and mental health

KEYwords: Noise, Hearing, Commercial Motor Bikers.

Department of Physiology*, Department of Surgery* * College of Medical Sciences, University of Benin, Benin City. Nigeria.

Corresponding Author: Dr Ahbor D A Ighoroje Postal address: P.O Box 10616, Ugbowo, Benin City,Edo State Nigeria. E-mail;dighoroje@yahoo.com ordighoroje@hotmail.com Tel: +23452 600781. Mobil +2348023366826, distortion, including hearing impairment and balance disorder ${ }^{2,3}$.

In some occupational groups, high noise levels can result in intolerable reactions and negatively impact on job satisfaction and performance ${ }^{4}$. With repeated and prolonged exposure to noise levels in the order of greater than $80 \mathrm{~dB}$ hearing impairment may occur ${ }^{5}$ The process of hearing impairment may be gradual but it can eventually result in the destruction of the hair cells of the organ of Corti. Apart from high noise causing acoustic trauma, it can cause a temporary or permanent shift in the hearing threshold ${ }^{5}$. The 
impairments may result in profound or total deafness.

NIHI can be caused by one time exposure to noise as well as repeated exposure to noise at various levels of loudness over an extended period. The usual conversation tone is at or less than $60 \mathrm{~dB}$. Exposure to a daily average noise level that is above $85 \mathrm{~dB}$ is dangerous because of damage to the hair cells. NIHI is hardly a matter of public health concern in many developing countries, such as Nigeria. There are few or poorly enforced noise pollution control laws in many parts of the country. Occupation is the main cause of hearing loss and traffic noise is a significant contributor ${ }^{6}$. The occupational groups exposed to noise pollution are hardly aware of the health risks of the noise levels at their places of work. There are also no protective measures in use among these workers to reduce the impact of noise on their health. The healthy ambient noise population level is usually above $60 \mathrm{~dB}^{7}$.

There is a definite critical level of noise and duration of exposure which trigger the process of hearing impairment. These critical levels vary with age, genetic make-up and previous exposure to loud noise.

The goal of this study was to determine the ambient noise levels in the motor bike parks which are along the major streets in Benin- City, Nigeria. The other objective was to assess the impact of these noise levels on hearing among the commercial motorbike riders. The onset of hearing impairment was also related to the duration of exposure of the individuals to the noise.

\section{MATERIALS AND METHODS}

\section{STUDY GROUP}

200 commercial motorbike riders (all males) aged between 20- 62 years were selected using the cluster sampling technique. Those selected had spent a minimum of one year on the job and were in no way provided with noise prevention aids. The riders carry out their business for a period of 10- 12 hours daily and 6- 7 days in a week and the mean exposure period of our study population was $4.7 \pm 2.7$ years.

A structural health and lifestyle questionnaire to elicit information from the workers was utilized in this study and the information elicited from the questionnaire formed the basis of selection of the 200 subjects.

The exclusion criteria applied included:

(1). Evidence of respiratory tract infection including common cold

(2). Smoking

(3). History of high blood pressure.

(4). History of treatment with toxic drugs including streptomycin.

(5). History of past ear trauma/ infection.

The rationale for the long list of exclusion criteria was to minimize the influence of the many confounding factors in the development of hearing impairment.

A group of 150 staff of the University of Benin Teaching Hospital (UBTH) and students of the University of Benin (UNIBEN) served as the control group. All volunteers gave their written/informed consent. The postgraduate research committee of the University of Benin approved the study.

\section{DETERMINATION OF AMBIENT NOISE}

The ambient noise levels of the five different park locations and the hospital were determined using a Noise meter (peters, UK). The ambient noise level was determined at four different times of the day namely: 9am, 12 noon, $3 \mathrm{pm}$ and $6 \mathrm{pm}$. The mean of these 
determinations was calculated. The aim of the time determination was to ascertain if there were peak periods for noise levels in these places.

\section{HEARING FUNCTION TEST}

The pure tone audiometric values of all the subjects at different sound frequencies (range of $125 \mathrm{~Hz} 8000 \mathrm{~Hz}$ ) were determined. The clinical staff of the ENT Surgery Department at the University of Benin Teaching Hospital assisted in performing these tests. The audiometry was done by screening Audiometer (Amplaid A 132). A pure tone audiometry for both Air Conduction (AC) and
Bone Conduction (BC) for the left and right ear $(\mathrm{AC} / \mathrm{BC})$ was determined.

The results were analyzed using the students't-test and Chi- Square.

\section{RESULTS}

Table 1 describes the ambient noise levels in the study locations, the mean age of the subjects and their noise exposure periods. The ambient noise levels in the five occupational locations was relatively higher with a range of $90-110 \mathrm{db}$ when compared to that of the teaching hospital and university campus both located in the same area with a range of $50-65 \mathrm{db}$.

TABLE I:

Some characteristics of the study population and their work location

\begin{tabular}{llll} 
INDEX & RANGE & MEAN & REMARKS \\
\hline Age (years) & 2062 & $37.1+2.1$ & \\
Exposure period (years) & 112 & $4.7+2.7$ & $\begin{array}{l}\text { 10-12 hrs/ day, } \\
6-7 \text { days/ week }\end{array}$ \\
$\begin{array}{l}\text { Ambient Noise level } \\
\text { in the study location }\end{array}$ & $90110 \mathrm{~dB}$ & $100 \pm 10 \mathrm{~dB}$ & Motor Bike Parks \\
$\begin{array}{l}\text { Ambient Noise level } \\
\text { In the control location }\end{array}$ & $5065 \mathrm{~dB}$ & $60+10 \mathrm{~dB}$ & Control location \\
& & & UBTH/UNIBEN \\
\hline
\end{tabular}

Table 2 shows a distribution of the proportion of workers developing air or bone conduction impairments in their right ear over the different exposure periods. Only $10 \%$ of the workers who have been exposed for 1-3 years developed determinable air conduction impairment compared to $50 \%$ for workers exposed for 7-9 years and 100\% for workers exposed for 10-12 years. Bone conduction impairment was less frequent than Air conduction impairment. By 4-6 years of exposure, only $10 \%$ of the workers had developed BCR impairment compared to $20 \%$ of workers who had ACR impairment. And by 10-12 years of exposure only $37 \%$ of workers had developed BCR impairment compared to $100 \%$ of workers with ACR impairment. 
TABLE 2:

Percent of workers who developed noise induced hearing impairment. ACR $=$ Air Conduction for the right ear. $\quad \mathbf{B C R}=$ Bone Conduction for the right ear.

\begin{tabular}{lll} 
EXPOSURE (yrs.) & TOTAL (N) & ACR \\
\hline $1-3$ & 80 & $8(10 \%)$ \\
$4-6$ & 80 & $16(20 \%)$ \\
$7-9$ & 24 & $12(50 \%)$ \\
$10-12$ & 16 & $16(100 \%)$ \\
\hline & & BCR \\
$1-3$ & 80 & $8(10 \%)$ \\
$4-6$ & 80 & $8(10 \%)$ \\
$7-9$ & 24 & $6(25 \%)$ \\
$10-12$ & 16 & $6(37 \%)$ \\
\hline
\end{tabular}

Table 3 shows the percent distribution of the workers who developed air or bone conduction impairment in the left ear (ACL or BCL impairment). There was a gradual but steady increase in the frequency of either Impairments but as was for ACR, air conduction was more affected than bone conduction. 30 of the workers exposed to noise pollution for 1-3 years suffered air conduction impairment compared to only $20 \%$ for bone conduction.By 10-12 years of exposure. $100 \%$ of the workers developed ACL impairment compared to only $50 \%$ for bone conduction.

\section{TABLE 3:}

Percent of workers who developed noise induced hearing impairment in the left ear, over different exposure periods.

$\mathrm{ACL}=$ Air Conduction for the left ear.

$\mathrm{BCL}=$ Bone Conduction for the left ear

\begin{tabular}{lll} 
EXPOSURE (yrs) & TOTAL (N) & ACL \\
\hline $1-3$ & 80 & $24(40 \%)$ \\
$4-6$ & 80 & $32(40 \%)$ \\
$7-9$ & 24 & $16(66 \%)$ \\
$10-12$ & 16 & $16(100 \%)$ \\
\hline & & BCL \\
$1-3$ & 80 & $16(20 \%)$ \\
46 & 80 & $24(30 \%)$ \\
$7-9$ & 24 & $8(33 \%)$ \\
1012 & 16 & $8(50 \%)$ \\
\hline
\end{tabular}


TABLE 4:

Percent of workers who developed AC/BC in both ears over different exposure periods.

$\mathrm{AC} / \mathrm{BC}=$ Air Conduction/Bone Conduction .

\begin{tabular}{lll} 
EXPOSURE & TOTAL $(\mathbf{N})$ & AC/BC \\
\hline $1-3$ & 80 & $32(40 \%)$ \\
$4-6$ & 80 & $40(50 \%)$ \\
$7-9$ & 24 & $24(100 \%)$ \\
$10-12$ & 16 & $16(100 \%)$ \\
\hline
\end{tabular}

Table 5 shows a comparison of both types of impairment in the left and right ears of the total number of subjects(200). $44 \%$ of the riders developed $\mathrm{AC}$ impairment in the left ear, 28\% developed BC impairment in the left ear. In comparison, $28 \%$ of the total number of riders developed AC impairment in the right ear while only 14\% developed BC impairment in the right ear.

\section{TTABLE 5:}

Total number of workers who developed NIHI. (Left ear compared with right ear)

$\mathrm{NIHI}=$ Noise induced hearing impairment.

$\mathrm{NI}=$ No impairment

$\mathrm{AC}=$ Air Conduction

$\mathrm{BC}=$ Bone Conduction

AC

BC

\begin{tabular}{lllll}
\hline & NIHI & NI & NIHI & NI \\
\hline Left Ear & 88 & 112 & 56 & 144 \\
Right Ear & 52 & 148 & 28 & 152 \\
\hline
\end{tabular}

\section{DISCUSSION}

It is note worthy that the local government of Benin- City has no regulations on noise pollution. In addition, the motor bike riders in the bike parks do not use any protective gears nor are they well aware of the possible health risks of noise pollution. Occupational noises pose important health risks, and form one of the biggest industrial diseases ${ }^{1}$. The paucity of regulatory measures against emission of loud noise and lack of protective gears by the riders increase the health risk posed by the loud noise in them.

The structure in the ear most susceptible to noise damage is the sensory receptor cell, the hair cells located in the cochlea. Damage to them from repeated noise is usually a physiochemical problem where the metabolic stress exerts pressure on the maximally stimulated cells which ultimately leads to cochlea damage ${ }^{5}$. After 1012 years, all the evaluated riders had developed hearing impairment and there was a clear correlation between length of exposure to 
noise level and the development of impairment in these group of riders.

There was an interesting asymmetry in hearing impairment for the left and right ears. Results show that air conduction in the right ear (ACR) was less than air conduction impairment in the left ear (ACL). The same trend is observable for bone conduction hearing impairment in the right ear which was less when compared to the left ear (BCR vs BCL) and these agree with Satterfield ${ }^{8}$ who reported hearing impairment asymmetry among soldiers with the left ear affected more than the right.

Findings in this study however contrast with Ighoroje et al ${ }^{9}$ who reported hearing impairment asymmetry among some industrial workers with the right ear more affected due to the fact that the source and direction of the sound was closer to the right ear in those subjects studied. The possible reason for this asymmetry in this study is uncertain. However inference can be made to the effect that the diffusion of sound coming out from the exhaust pipes located on the right side of the bike is most probably directed towards the back on the left side. Also since in Nigeria driving is on the right, the noise on the left side is more and the left ear is more affected thus making it to be more directly exposed to the sound than the right ear resulting in more damage in the left ear. It is yet uncertain which of the two ears is more susceptible to damage by noise, but persistent stimulation of any ear and firing of the hair cells can lead to wear, tear and adaptive changes. Sensorineural damage results more often from noise pollution compared with bone conduction deafness ${ }^{8}$ and this partly explains the findings in this study of lower frequency of hearing impairment for bone conduction than for air conduction.

From this study, the critical exposure period to noise appears to be between 7-9 years in contrast to 4-5 years as earlier reported by Ighoroje et al ${ }^{9}$. By 1012 years majority of the study population had developed detectable impairment which suggests a gradual but steady development of hearing impairment. Age is a notable factor in NIHI development. Older subjects above 40 years are reportedly at greater risk [7].The ages of subject in this study were generally below 40 (i.e. mean age of 37.12.1).

NIHI occurred mostly at higher frequency range of $3000-6000 \mathrm{~Hz}$ with largest effects observed at $4000 \mathrm{~Hz}$.With increasing exposure time to noise, NIHI was also seen at lower frequencies such as $2000 \mathrm{~Hz}$. Findings in this study were consistent with similar work done by Satal off ${ }^{10}$.

In conclusion loud noise certainly endangers health of motor bike riders; the findings here provide further evidence for this. Beyond impairment of hearing, loud noise affects several other physiological processes of the body as well as mental well being. Hearing impairment similarly has its many psycho-physiological consequences. The various levels of Government in developing Countries will need to put policies in place and ensure strict compliance to protect different occupational groups, including commercial motorbike riders whose business is becoming one of the fastest growing means of transportation in Nigeria. Hopefully the findings will serve to inform the policy makers in government and the industry to institute control and safety measures to protect their workers and to raise the level of awareness of these workers on the health risks of their work environment and thus stimulate them to use protective gears.

\section{ACKNOWLEDGEMENT}

We sincerely express our appreciation to the clinical staff of the Ear Nose and Throat, Surgery Department at the University of Benin Teaching hospital especially Mr Ojuigo who assisted in performing some of these tests. 


\section{References}

1. Sataloff RT, and Sataloff J, 1987. Occupational hearing loss. New York: Marcel Dekker.

2. Ylikoki J, Juntunen J,Maintiainen E, Ylikoski M and Ojala M, 1988.Sub clinical Vestibular pathology in patients with noise- induced hearing loss from intense impulse noise. Acta Otolaryngology. 105: 588-563

3. Satterfield K, 2001. Balance disorders and patients with NIHI in one ear. America Academy of otolaryngology Head and Neck Surgery.703:1-3

4. Burns W and Robinson D.W, 1970. Hearing and Noise in Industry: London; HMSO.

5. Harris C.M, 1979. Hand book of noise control ( $2^{\text {nd }}$ Ed). New York; McGraw Hill.

6. Mansfield J.D and Baghurst P.A, 1999 Otoacoustic emissions in 28 young adults exposed to amplified music $\mathrm{Br}$. J Audiol. Aug; 33 (4):211-22. 